\title{
Evidence of multiple mechanisms providing carbamate and organophosphate resistance in field An. gambiae population from Atacora in Benin
}

Rock Aïkpon ${ }^{1,2^{*}}$, Michel Sèzonlin², Razaki Ossè ${ }^{1,2}$ and Martin Akogbéto ${ }^{1,2}$

\begin{abstract}
Background: Insecticide resistance in Anopheles gambiae s.l is a major concern to malaria vector control programmes. In West Africa, resistance is mainly due to target-site insensitivity arising from a single point mutation. Metabolic-based resistance mechanisms have also been implicated and are currently being investigated in west Africa. The aim of this study is to better understand the origins of carbamate and organophosphate resistance in An. gambiae population from Atacora, Benin in West Africa.
\end{abstract}

Methods: Anopheles mosquitoes were reared from larvae collected in two districts (Kouandé and Tanguiéta) of the Atacora department. Mosquitoes were then exposed to WHO impregnated papers. Four impregnated papers were used: carbamates $(0.1 \%$ bendiocarb, $0.1 \%$ propoxur) and organophosphates $(0.25 \%$ pirimiphos methyl, $1 \%$ fenitrothion). PCR assays were run to determine the members of the An. gambiae complex, as well as phenotypes for insensitive acetylcholinesterase (AChE1). Biochemical assays were also carried out to detect any increase in the activity of enzyme typically involved in insecticide metabolism (oxidase, esterase and glutathion-S-transferase).

Results: 769 female of An. gambiae mosquitoes from Kouandé and Tanguiéta were exposed to bendiocarb, propoxur, pirimiphos methyl and fenitrothion. Bioassays showed resistance with low mortality to bendiocarb (78.57\% to $80.17 \%)$, propoxur (77.21\% to $89.77 \%)$, and fenitrothion (89.74\% to $92.02 \%)$. On the other hand, the same populations of An. gambiae from Kouandé and Tanguiéta showed high susceptibility to pirimiphos methyl with recorded mortality of $99.02 \%$ and $100 \%$ respectively. The low rate of ace-1R allele frequency $(3.75 \%$ among survivors and $0.48 \%$ among dead) added to the high proportion of homozygous susceptible specimens which survived the WHO bioassays (8/28), suggest that the ace-1 mutation could not entirely explain Anopheles gambiae resistance to carbamate and organophosphate. Biochemical assays suggest that resistance in this population is mediated by metabolic resistance with elevated level of GST, MFO and NSE compared to a susceptible strain An. gambiae Kisumu.

Conclusions: Anopheles gambiae populations resistance from Atacora is multifactorial and includes target-site mutation and metabolic mechanism. The co-implication of both resistance mechanisms in An. gambiae s.l may be a serious obstacle for the future success of malaria control operations based on LLINs and IRS.

Keywords: Resistance mechanisms, Carbamate, Organophosphate, Anopheles gambiae, Benin

\footnotetext{
* Correspondence: rockypremier@yahoo.fr

'Centre de Recherche Entomologique de Cotonou (CREC), 06 BP 2604, Cotonou, Bénin

${ }^{2}$ Faculté des Sciences et Techniques, Université d'Abomey Calavi, Calavi, Bénin
}

\section{Biomed Central}

(C) 2014 Aikkon et al.; licensee BioMed Central Ltd. This is an Open Access article distributed under the terms of the Creative Commons Attribution License (http://creativecommons.org/licenses/by/4.0), which permits unrestricted use, distribution, and reproduction in any medium, provided the original work is properly credited. The Creative Commons Public Domain Dedication waiver (http://creativecommons.org/publicdomain/zero/1.0/) applies to the data made available in this article, unless otherwise stated. 


\section{Background}

Malaria is a main cause of mortality and morbidity and Anopheles gambiae is one of the major vectors of this desease in sub-Saharan Africa [1]. The current effective vector control tools include the use of Long Lasting Insecticide Nets (LLIN) and Indoor Residual Spraying (IRS) [2]. The success of such interventions requires a good knowledge of vector populations particulary their susceptibility status to the main insecticides used for such control programmes in order to detect and monitor resistance to these insecticides.

Pyrethroids are the only group of insecticides currently recommended for net treatment and the other classes of insecticides (organochlorine, carbamate and organophosphate) are applied for IRS [3,4]. The main problem with LLINs and IRS is the development of insecticide resistance, particularly pyrethroid-resistance by several populations of An. gambiae [5-8]. Recently, the emergence of resistance in populations of An. gambiae to common classes of insecticides used in public health has been reported in many countries in Africa, including Côte d'Ivoire [5,9], Kenya [10], Benin [11,12], Niger [13], Burkina Faso [14], Mali [15], Nigeria [16,17], South Africa [18] and Cameroon [19]. More recently in Benin, several studies pointed out An. gambiae resistance to bendiocarb $[20,21]$ and showed that the mean Ace-1 mutation frequency had increased significantly from 2010 to 2012 after two years of IRS campaign using bendiocarb in Atacora region in the northern part of the country $[22,23]$. However, these studies cleary showed the evidence of bendiocarb resistance in An. gambiae populations but mentioned the ace-1R mutation could not entirely explain the resistance to bendiocarb observed.

The aim of this study is to better understand the origins of carbamate and organophosphate resistance in An. gambiae population from Atacora. We conducted bioassays, molecular and biochemical analysis to update resistance status in An. gambiae and detect other potential mechanisms of resistance that might have evolved.

\section{Methods}

\section{Study area}

The study was carried out in Atacora region located in the North-west of Benin and includes two districts: Kouandé and Tanguiéta (Figure 1). The two districts covered $5,128 \mathrm{~km} 2$ and had an estimated population of 198,956 in 2012. Atacora region has a sub-equatorial type climate with one dry season (December-May) and only one rainy season (June to November). The annual mean rainfall is $1,300 \mathrm{~mm}$ and the mean monthly temperature ranges between 22 and $33^{\circ} \mathrm{C}$. The region is irrigated by three major rivers: the Mekrou, the Pendjari and the Alibori. The major economic activity is agriculture and it is characterized by the production of cotton and millet where various classes of pesticides are used for pest control. Since 2011 onwards the department has conducted a large scale Indoor Residual Spraying (IRS) campaign.

\section{Mosquito collections}

Anopheles gambiae s.l. larvae were collected in 2 districts and in each district, two villages were selected randomly. At each locality chosen, Anopheline larvae were collected from various natural breeding sites including ground pools, gutters, puddles and abandoned potholes, at the begining of the rainy season during June 2014. Water was scooped using a plastic scoop and poured into small transparent plastic bowls. A strainer was used to sieve and pool together the third and fourth instar larvae in order to have sufficient adult emergence of the same physiological age. The mosquito larvae collected were transported in well labelled plastic bottles to the laboratory of the Centre de Recherche Entomologique de Cotonou, Benin (CREC) where they were maintained at $28 \pm 2 \mathrm{C}$ and $72 \pm 5 \%$ relative humidity. A laboratory susceptible strain of $A n$. gambiae Kisumu was used as a reference strain to compare the susceptibility levels of the field populations.

\section{Insecticide susceptibility tests}

Mosquitoes collected were assayed using WHO discriminating dosages with four insecticides of technical grade quality: two carbamates ( $0.1 \%$ propoxur, $0.1 \%$ bendiocarb) and two organophosphates (1\% fenitrothion, $0.25 \%$ pirimiphos méthyl). Four batches of 25 unfed females, aged 2-5 days, were exposed to the diagnostic doses of insecticide treated papers for $60 \mathrm{~min}$ at $27 \pm 1^{\circ} \mathrm{C}$ and $80 \%$ relative humidity. The twenty-five females of $A n$. gambiae were introduced into each tube and monitored at different time intervals $(10,15,20,30,45,60$ minutes), the number "knocked-down" were recorded. After one hour exposure, mosquitoes were transferred into holding tubes and provided with cotton wool soaked with a $10 \%$ honey solution. Batches exposed to untreated papers were used as control. Mortalities were recorded after 24 hours and the susceptibility status of the population was graded according to the WHO protocol [24]. Dead and surviving mosquitoes from this bioassay were kept separately in eppendorf tubes containing silica gel and stored at $-20^{\circ} \mathrm{C}$ for further molecular analysis.

\section{Species identification and PCR detection of Ace-1R mutation}

Live and dead specimens of An. gambiae from the bioassay tests were subjected to the An. gambiae species specific PCR assays for species identification [25,26]. The PCR-RFLP diagnostic test was used to detect the presence of G119S mutation (ace.1R gene). Mosquito genomic DNA was amplified using the primers 


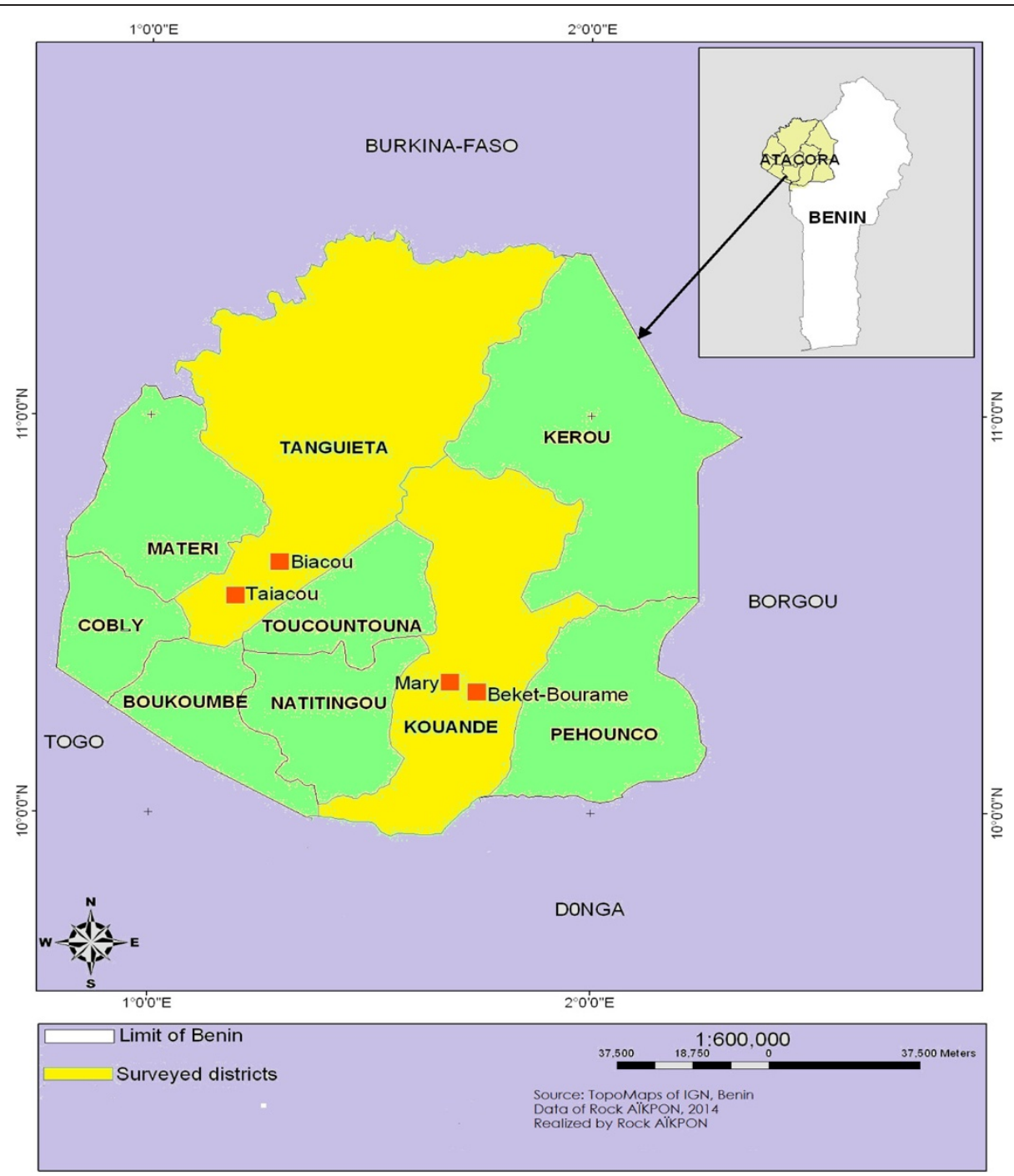

Figure 1 Map of the departement of Atacora showing the localities where Anopheline mosquitoes were collected.

Ex3AGdir 5' GATCGTGGACACCGTGTTCG3' and Ex3AGrev 5'AGGATGGCCCGCTGGAACAG3' according to [27]. One microlitre of total DNA extracted from a single mosquito was used as a template in a $25 \mathrm{ml}$ PCR reaction containing Taq DNA polymerase buffer, $0.2 \mathrm{mM}$ dNTP and 10 pmol of each primer. The PCR conditions were $94^{\circ} \mathrm{C}$ for $5 \mathrm{~min}$ and then 35 cycles of $\left(94^{\circ} \mathrm{C}\right.$ for $30 \mathrm{~s}$, $54^{\circ} \mathrm{C}$ for $30 \mathrm{~s}$ and $72^{\circ} \mathrm{C}$ for $30 \mathrm{~s}$ ) with a final 5 min extension at $72^{\circ} \mathrm{C}$. Fifteen microlitres of PCR product were digested with $5 \mathrm{U}$ of AluI restriction enzyme (Promega) in a final volume of $25 \mathrm{ml}$. The PCR fragments were fractionated on a $2 \%$ agarose gel stained with ethidium bromide and visualized under UV light.

\section{Biochemical analysis}

Biochemical assays were performed to compare the levels of activity of mixed function oxidases (MFO), non-specific esterases (NSE) using a-naphtyl acetate as a substrate and glutathione S-transferases (GST) [28] in the An. gambiae s.s. susceptible Kisumu and the field population from Tanguiéta and Kouandé districts. Mosquitoes used for the biochemical analysis have not been exposed to any insecticides prior to the assay.

Detoxifying enzyme activities were measured on single mosquitoes $(\mathrm{N}=50)$ from each test locality, which were stored at $280 \mathrm{uC}$ within $24 \mathrm{~h}$ from emergence (above). Each mosquito was ground on ice in $200 \mu \mathrm{l}$ of distilled water and the homogenate was centrifuged at $1,4000 \mathrm{rpm}$ for 2 mins. Two $10 \mathrm{ml}$ replicates of supernatant were transferred into two adjacent wells of a microtitre plate for non-specific esterases (NSEs), gluthatione Stransferases (GSTs). Monooxygenases assays were performed with two $20 \mathrm{ml}$ replicates of supernatant. 


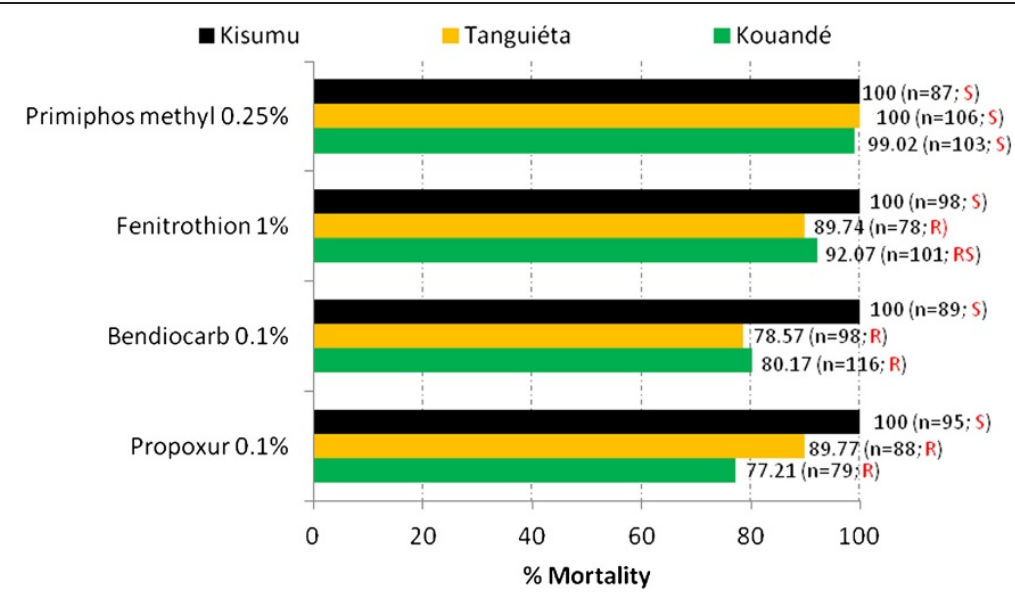

Figure 2 Mortality rates in Anopheles gambiae 24-hours post exposure to propxur $0.1 \%$, bendiocarb $0.1 \%$, fenitrothion $1 \%$ and pirimiphos methyl $\mathbf{0 . 2 5 \%}$. $S$ = susceptible; $R=$ resistant; $R S$ = resitance suspected.

\section{Non-specific esterases (NSEs)}

Non-specific esterase activity was measured using anaphtol acetate $(\mathrm{aNa})$ and b-naphtol acetate $(\mathrm{bNa})$. In each replicate well, $90 \mathrm{ml}$ of phosphate buffer (PBS, $\mathrm{pH}=6.5$ ) and $100 \mathrm{ml}$ of $0.6 \mathrm{M}$ aNa (or bNa) were added to $10 \mathrm{ml}$ of centrifuged mosquito homogenate. After 30 min incubation, $100 \mathrm{ml}$ of Fast Garnett BC solution (8 g Fast Garnett Salt $+10 \mathrm{ml}$ distilled water) was added to stop the reaction. The concentration of the final product was determined at $550 \mathrm{~nm}$ as an endpoint calculated from standard curves of a- and b-Naphtol, respectively.

\section{Glutathione-S-transferases (GST)}

To measure glutathione- S-transferase (GST) activity in mosquitoes, $200 \mathrm{ml}$ of GSH/CDNB working solution (100 $\mathrm{ml}$ of an extemporaneous solution of $0.6 \%$ weight/ volume reduced glutathione in $0.1 \mathrm{M}$ sodium phosphate buffer $\mathrm{pH}=6.5+0.013 \mathrm{~g}$ of 1-chloro-2, 4-dinitrobenzene diluted in $1 \mathrm{ml}$ of $70 \%$ methanol) were added to each replicate of mosquito homogenate. The reaction was read at $340 \mathrm{~nm}$ immediately as a kinetic assay for $5 \mathrm{mi}$ nutes. An extinction coefficient of $5.76 \mathrm{mM}^{-1}$ (corrected for a path length of $0.6 \mathrm{~cm}$ ) was used to convert absorbance values to moles of product. GST specific activity was reported as the rate of formation of GSH produced in $\mathrm{mmol} . \mathrm{min}^{-1} . \mathrm{mg}^{-1}$ protein.

\section{Oxydases (Cytochrome P450)}

Cytochrome P450 activity was determined using the heme-peroxidase assay according to Brogdon et al. [29]. The assay detects the elevation in the amount of heme, which is then converted into equivalent units of cytochrome P450. Eighty $\mathrm{ml}$ of $0.625 \mathrm{M}$ potassium phosphate buffer ( $\mathrm{pH}=7.2$ ) were added to $20 \mathrm{ml}$ of mosquito homogenate together with $200 \mathrm{ml}$ Tetramethyl Benzidine solution (0.011 g 3,3,5,5' Tetramethyl Benzidine in $5 \mathrm{ml}$ of
$70 \%$ methanol $+15 \mathrm{ml}$ sodium acetate buffer $0.25 \mathrm{M}$ $\mathrm{pH}=5.0) ; 25 \mathrm{ml}$ of $3 \%$ hydrogen peroxide were then added and the mixture was incubated for $30 \mathrm{~min}$ at room temperature. Absorbance was read at $630 \mathrm{~nm}$ and values calculated from a standard curve of cytochrome C.

\section{Data analysis}

The resistant status of mosquito samples was determined according to the WHO criteria [23]:

- Mortality rate is $>98 \%$ : the population was considered fully susceptible

- Mortality rates ranged between 90 - 98\%: resistance suspected in the population

- Mortality rates $<90 \%$, the population was considered resistant to the tested insecticides

Allelic frequencies of G119S mutation were analysed using the version 1.2 of Genepop [30].

To assess if the mutation frequencies were identical across populations, the test of genotypic differentiation was performed [31]. Biochemical assay data (enzymatic activity per mg of protein) of wild specimens of An. gambiae s.l were compared to the Kisumu susceptible strain using Mann-Whitney non-parametric $U$-test (Statistica software).

\section{Results}

Bendiocarb and organophosphate susceptibility status of Anopheles gambiae s.l

A total of 769 female of An. gambiae mosquitoes (3-5 days old) from Kouandé and Tanguiéta were exposed to bendiocarb $(n=214)$, propoxur $(n=167)$, pirimiphos methyl $(n=209)$ and fenitrothion $(n=179)$. Mortality rates of the Kisumu reference strain to all insecticides was $100 \%$ (Figure 2). In contrast, wild mosquitoes were 
high resistant with mortality rates less than $90 \%$ for bendiocarb (80.17\% and $78.57 \%$ ) and propoxur $(77.21 \%$ and $89.77 \%$ ) in Kouandé and Tanguiéta respectively (Figure 2). As for the organophosphates, susceptibility to pirimiphosmethyl was assessed on all populations. Mortality rate were higher than $98 \%$ as per WHO criteria with $99.02 \%$ recorded in Kouandé and $100 \%$ in Tanguiéta. However, fenitrothion resistance was detected in Kouandé and Tanguiéta, with mortality rates of $92.07 \%$ and $89.74 \%$ respectively.

\section{PCR- species identification}

One hundred mosquitoes were identidied to Anopheles gambiae species. All PCR analysis identifying An. gambiae s.l species in this study confirmed that all mosquitoes belonging to An. gambiae s.l were An. gambiae.

\section{Involvement of ace-1R mutation in providing carbamate and organophosphate resistance}

To assess the role of the ace- $1 \mathrm{R}$ allele in conferring carbamate and organophosphate resistance in An. gambiae population, the ace-1R genotype was determined for dead and alive mosquitoes detected in the WHO bioassay using carbamate and organophosphate (Figure 3). A total of 59 mosquitoes were tested of which 31 dead and 28 alive. Among both bioassay survivors and nonsurvivors, all ace- $1 \mathrm{R}$ genotypes (RR, RS and SS) were found. However, the homozygous resistant genotype RR was only found among the bioassay survivors, and the heterozygote genotype RS was the most prevalent genotype among the bioassay survivors. Although there was a significant ace-1R genotype differentiation between bioassay survivors and non-survivors $(\mathrm{p}<0.0001)$, homozygous susceptible mosquitoes were found among bioassay survivors.

\section{Biochemical assays}

Biochemical assays were successfully performed on the two An. gambiae populations (Tanguiéta and Kouandé) from Atacora. Figure 4 shows the mean level of enzymatic activity (MFO, NSE and GST) in field-collected mosquitoes compared to the reference susceptible strain Kisumu. All sampled populations showed a significantly higher MFOs activity (expressed in cytochrome P450 units) than the susceptible reference strain Kisumu $(\mathrm{p}<0.005)$. The level of esterase activity (using alpha and beta naphtyl acetate as a substrate) did not reveal any significant differences between Kisumu and Kouandé An. gambiae population ( $\mathrm{p}=$ 0.65). Overall, the mean level of alpha and beta esterase activity in Tanguiéta was significantly higher than that of the susceptible strain $(\mathrm{p}<0.05)$. Besides, all sampled populations showed a significantly higher GST activity than the susceptible reference strain Kisumu $(\mathrm{p}<0.05)$.

\section{Discussion}

This study highlighted the diversity of carbamate and organophosphate resistance in Anopheles gambiae s.l. populations from Atacora in Benin. The results presented here show that carbamate and organohosphate resistance in sampled Anopheles gambiae populations is multifactorial and includes target-site mutation and metabolic mechanism in this region.

An. gambiae displayed large variations in resistance levels to carbamates and organophosphates. Although the wild populations were all resistant to bendiocarb, resistance was less marked to propoxur and fenitrothion, at WHO diagnostic concentrations. However, all these populations were very susceptible to pirimiphos-methyl. This resistance of the mosquito population to carbamate and fenitrothion would be due to the strong selective pressure that represents the use of insecticides in households for public health purposes, notably IRS using bendiocarb [21] and massive quantities of carbamates and organophosphates in agricultural settings in the department of Atacora. Indeed, in the cotton growing areas in Atacora, farmers use huge amounts of insecticides to avoid substantial yield reduction of their crops. Several studies showed that agricultural practices seem to have

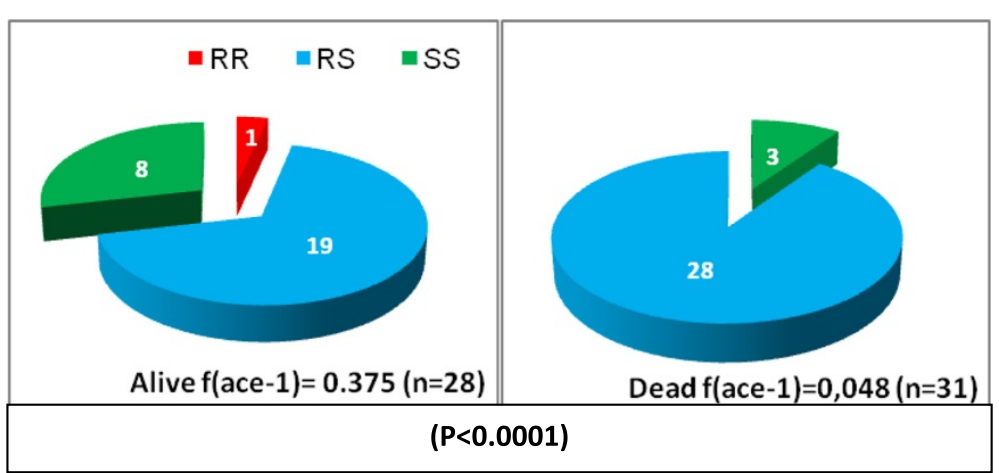

Figure 3 Ace-1 genotypes distribution among live and dead An. gambiae s.s individuals from WHO susceptibility test to carbamate and organophosphate. 
contributed to the emergence of insecticide resistance in Anopheles populations [8,12,32].

Cross-resistance to organophosphates and carbamates suggests the involvement of their common target-site: AChE-1 [33]. The high proportion of homoygous susceptible specimens, which survived the WHO bioassays, added to the low rate of ace- $1 \mathrm{R}$ allele frequency suggest that the ace-1 mutation could not entirely explain Anopheles gambiae resistance to carbamate and organophosphate.

In the present study, the low ace-1 mutation frequency in sampled An. gambiae populations associated with the resistance to carbamate and organophosphate strongly supports the involvement of metabolic resistance based on the high activities of typical enzymes NSE, GST and MFO. Similar findings have been reported in Culex quinquefasciatus and Anopheles gambiae in four other sites in Benin, where greater oxidase and esterase activities were observed in C.x quinquefasciatus and $A n$. gambiae, but where ace-1 was absent [34]. The same findings were also reported in the field experimental station of Pito (Cameroun) [35,36].

Considering the mutiple insecticide resistance mechanisms in An. gambiae s.l population from Atacora, resistance management becomes a particulary important issue. Insecticide rotation or synergistic use of different classes of insecticides to enhance the killing effects are being considered as alternative methods of vector control to slow down the spread of resistance genes.

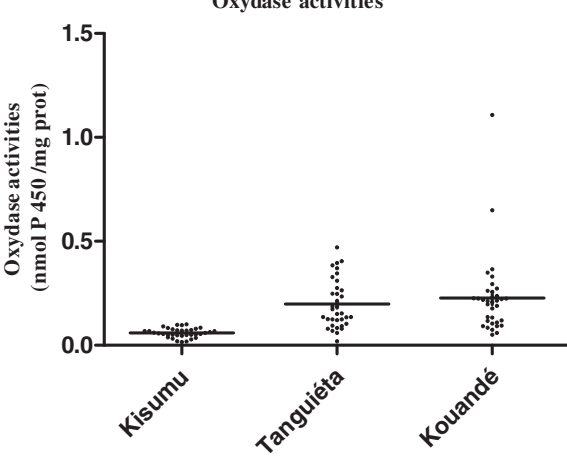

Localities

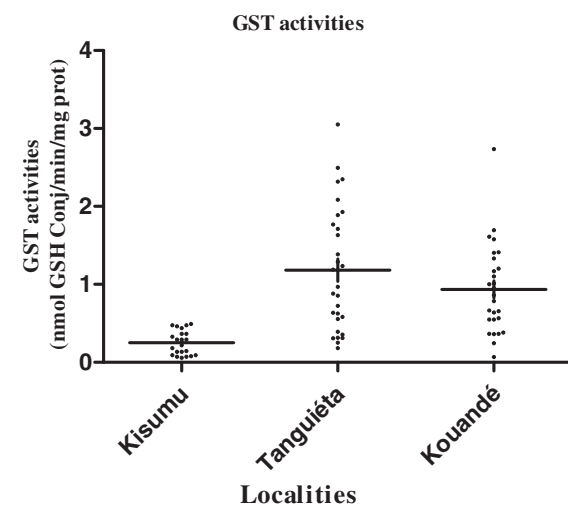

Figure 4 Detoxifying enzyme activities in An. gambiae mosquitoes collected form two districts in Ataccora departement.

\section{Conclusions}

The present study revealed the simultaneous presence of multiple resistance mechanisms in malaria vector $A n$. gambiae s.l population from Atacora. The co-implication of both metabolic and ace-1 resistance mechanisms in An. gambiae s.l may be a serious obstacle for the future success of malaria control operations based on LLINs and IRS. Altenative innovative vector control tools are therefore urgently needed to manage these complex mechanisms and to complement insecticide-based strategies.

\section{Competing interests}

The authors declare that they have no competing interests.

\section{Authors' contributions}

RA, MS, RO, and MA designed the study. RA and MA carried out the field activities. RA drafted the manuscript and analyzed the data. RO and MS critically revised the manuscript. RA conceived and designed the study and revised the manuscript for intellectual content. All authors read and approved the final manuscript.

\section{Acknowledgements}

This work was financially supported by PMI (President's Malaria Initiative) through USAID. We thank the team of CREC for their technical assistance during field work. We also thank the people of Atacora for their collaboration.

Received: 28 September 2014 Accepted: 24 November 2014 Published online: 02 December 2014 


\section{References}

1. Gillies MT, Coetzee M: A supplement to the anophelinae Africa South of the Sahara (Afrotropical region), Johannesburg, South Africa. S Afr Inst Med Res 1987, 55:1-143.

2. Beier JC, Keating J, Githure JI, Macdonald MB, Impoinvil DE, Novak RJ: Integrated vector management for malaria control. Malaria J 2008, 7(supp1):54

3. Guillet P, Chandre F, Mouchet J: L'utilisation des insecticides en santé publique: état et perspectives. Med Mal Infect 1997, 27:552-557.

4. Devine GJ, Ogusuku E: Adaptability is key when monitoring insecticide resistance. Bull World Health Organ 2009, 87:887.

5. Elissa N, Mouchet J, Riviere F, Meunier JY, Yao K: Resistance of Anopheles gambiae s.s. to pyrethroids in Côte-d'Ivoire. Ann Soc Belge Med Trop 1993, 73:291-294.

6. Akogbéto M, Yakoubou S: Résistance des vecteurs du paludisme vis-à-vis des pyréthrinoïdes utilisés pour l'imprégnation des moustiquaires au Bénin, Afrique de l'Ouest. Bull Soc Pathol Exot 1999, 92:123-130.

7. Chandre F, Darriet F, Duchon S, Finot L, Manguin S, Carnevale P, Guillet P: Modifications of pyrethroid effects associated with kdr mutation in Anopheles gambiae. Med Vet Entomol 2000, 14:81-88.

8. Akogbeto M, Djouaka RF, Kinde-Gazard DA: Screening of pesticide residues in soil water samples from agricultural settings. Malaria J 2006, 5:22.

9. Ahoua-Alou LP, Koffi AA, Adja MA, Tla E, Kouassi PK, Kone M, Chandre F: Distribution of ace-1R and resistance to carbamates and organophosphates in Anopheles gambiae s.s. populations from Côte d'Ivoire. Malaria J 2010, 9:167.

10. Vulule JM, Beach RF, Atieli FK, MCAllister JC, Brogdon WG, Roberts JM, Mwangi RW, Hawley WA: Elevated oxidase and esterase levels associated with permethrin tolerance in Anopheles gambiae from Kenyan villages using permethrin impregnated nets. Med Vet Entomol 1999, 13:239-244.

11. Aïzoun N, Aïkpon R, Padonou GG, Oussou O, Oké-Agbo F, Gnanguenon V, Ossè R, Akogbéto M: Mixed-function oxidases and esterases associated with permethrin, deltamethrin and bendiocarb resistance in Anopheles gambiae s.l in the south-north transect Benin, West Africa. Parasit Vectors 2013, 6:223

12. Yadouleton AW, Asidi A, Djouaka RF, Braïma J, Agossou CD, Akogbeto MC Development of vegetable farming: a cause of the emergence of insecticide resistance in populations of Anopheles gambiae in urban areas of Benin. Malaria J 2009, 8:103.

13. Czeher C, Labbo R, Arzika I, Duchemin JB: Evidence of increasing Leu-Phe knockdown resistance mutation in Anopheles gambiae from Niger following a nationwide longlasting insecticide-treated nets implementation. Malaria J 2008, 7:189.

14. Diabate A, Baldet T, Chandre F, Guiguemde RT, Brengues C, Guillet P, Hemingway J, Hougard JM: First report of the kdr mutation in Anopheles gambiae M form from Burkina Faso, West Africa. Parassitologia 2002, 44:157-158.

15. Fanello C, Petrarca V, Della Torre A, Santolamazza F, Dolo G, Coulibaly M, Alloueche A, Curtis CG, Toure YT, Coluzzi M: The pyrethroid knock-down resistance gene in the Anopheles gambiae complex in Mali and further indication of incipient speciation within An. gambiae s.s. Insect Mol Biol 2003, 12:241-245.

16. Awolola TS, Brooke BD, Koekemoer LL, Coetzee M: Resistance of the malaria vector Anopheles gambiae s.s. to pyrethroid insecticides, in south-western Nigeria. Ann Trop Med Parasitol 2002, 96:849-852.

17. Oduola AO, Idowu ET, Oyebola MK, Adeogun AO, Olojede JB, Otubanjo OA, Awolola TS: Evidence of carbamate resistance in urban populations of Anopheles gambiae s.s. mosquitoes resistant to DDT and deltamethrin insecticides in Lagos, South-Western Nigeria. Parasit Vectors 2012, 5:116.

18. Hargreaves K, Koerkemoer LL, Brooke B, Hunt RH, Mthembu J, Coetzee M: Anopheles funestus resistant to pyrethroid insecticides in South Africa. Med Vet Entomol 2000, 14:181-189.

19. Etang J, Manga L, Chandre F, Guillet P, Fondjo E, Mimpfoundi R, Toto JC, Fontenille D: Insecticide susceptibility status of Anopheles gambiae s.l. (Diptera: Culicidae) in the Republic of Cameroon. J Med Entomol 2003, 40:491-497.

20. Aiikpon R, Agossa R, Ossè R, Oussou O, Aïzoun N, Oké-Agbo F, Akogbéto M: Bendiocarb resistance in Anopheles gambiae s.l. populations from Atacora department in Benin, West Africa: a threat for malaria vector control. Parasit Vectors 2013, 6:192.
21. Aïzoun N, Aïkpon R, Gnaguenon V, Oussou O, Agossa F, Padonou GG, Akogbéto M: Status of organophosphate and carbamate resistance in Anopheles gambiae sensu lato from the south and north Benin, West Africa. Parasit Vectors 2013, 6:274.

22. Aïkpon R, Aïzoun N, Sovi A, Oussou O, Govoetchan R, Gnanguenon V, Oké-Agbo R, Ossè R, Akogbéto M: Increase of Ace-1 resistance allele in the field population of Anopheles gambiae following a large scale indoor residual spraying (IRS) implementation using bendiocarb in Atacora region in Benin, West Africa. J Cell Anim Biol 2014, 8(1):15-22.

23. Aïkpon R, Aïzoun N, Ossè R, Oké-Agbo R, Oussou O, Govoetchan R, Sovi A, Akogbéto M: Seasonal variation of Ace-1R mutation in Anopheles gambiae s. I. populations from Atacora region in Benin, West Africa. J Entomol Nematol 2014, 6(1):14-18

24. WHO: Guidelines for Testing Mosquito Adulticides Intended for Indoor Residual Spraying (IRS) and Insecticide Treated Nets (ITNs). Geneva: WHO/CDS/NTD/ WHOPES/GCDDP/2006.3; 2006:2.

25. Scott J, Brogdon W, Collins F: Identification of single specimens of the Anopheles gambiae complex by PCR. Am J Trop Med Hyg 1993, 49:520-529.

26. Favia G, Lanfrancotti A, Spanos L, Siden-Kiamos I, Louis C: Molecular characterization of ribosomal DNA polymorphisms discriminating among chromosomal forms of Anopheles gambiae s.s. Insect Mol Biol 2001, 10:19-23.

27. Weill M, Lutfalla G, Mogensen K, Chandre F, Berthomieu A, Berticat C, Pasteur N, Philips A, Fort P, Raymond M: Insecticide resistance in mosquito vectors. Nature 2003, 423:136-137.

28. Hemingway J: Techniques to Detect Insecticide Resistance Mechanism (Field and Laboratory Manual). Document WHO/CDS/CPC/MAL/98.6. Geneva Switzerland: World Health Organ; 1998.

29. Brogdon WG, MCAllister JC: Insecticide resistance and vector control. Emerg Infect Dis 1998, 4:605-613.

30. Raymond M, Rousset F: Genepop (version 1.2), population genetics software for exact tests and eucumenicism. J Heredity 1995, 86:248-249.

31. Goudet J, Raymond M, De Meeüs T, Rousset F: Testing differentiation in diploid populations. Genetics 1996, 144:1933-1940.

32. Diabaté A, Baldet T, Chandre F, Akogbeto M, Guiquemde TR, Darriet F, Brengues C, Guillet P, Hemingway J, Small GJ, Hougard JM: The role of agricultural use of insecticides in resistance to pyrethroids in Anopheles gambiae s.l. in Burkina Faso. Am J Trop Med Hyg 2002, 67:617-622.

33. Weill M, Malcolm C, Chandre F, Mogensen K, Berthomieu A, Marquine M, Raymond $\mathrm{M}$ : The unique mutation in Ace-1 giving high insecticide resistance is easily detectable in mosquito vectors. Insect Mol Biol 2004, 13:1-7.

34. Corbel V, N'Guessan R, Brengues C, Chandre F, Djogbénou L, Martin T, Akogbéto M, Hougard JM, Rowland M: Multiple insecticide resistance mechanisms in Anopheles gambiae and Culex quinquefasciatus from Benin, West Africa. Acta Trop 2007, 101:207-216

35. Etang J, Manga L, Toto JC, Guillet P, Fondjo E, Chandre F: Spectrum of metabolic-based resistance to DDT and pyrethroids in Anopheles gambiae s.l. populations from Cameroon. J Vect Ecol 2007, 32:123-133.

36. Chouaibou M, Simard F, Chandre F, Etang J, Darriet F, Hougard JM: Efficacy of bifenthrin-impregnated bednets against Anopheles funestus and pyrethroid-resistant Anopheles gambiae in North Cameroon. Malar J 2006, 5:77.

doi:10.1186/s13071-014-0568-5

Cite this article as: Aikpon et al.: Evidence of multiple mechanisms providing carbamate and organophosphate resistance in field $A n$. gambiae population from Atacora in Benin. Parasites \& Vectors 2014 7:568. 